\title{
Uso de escória de aciaria em misturas asfálticas de módulo elevado
}

\author{
Hérika Braga de Freitas ${ }^{1}$; Laura Maria Goretti da Motta²
}

\begin{abstract}
Resumo: Avaliou-se o emprego de escória de aciaria na produção de misturas asfálticas de módulo elevado, aliando a necessidade de novas técnicas construtivas, que exijam menores freqüências de manutenção e apresente maior durabilidade, ao mesmo tempo em que se reduz custo e dano ambiental. Essas misturas, conhecidas por EME (enrobé à module élevé), são comumente utilizadas em camadas de base ou ligação na França. São comparadas, através de ensaios de módulo de resiliência, resistência à tração, fadiga, creep e análise mecanística, misturas asfálticas compostas por agregado convencional e por escória de aciaria. Mostrou-se que é viável a utilização de escória para produção de misturas asfálticas EME.
\end{abstract}

\begin{abstract}
The possibility of using steel slag as gravel in high modulus asphalt mixtures was verified. It was also studied, for comparison, mixtures with the same gradation and cement types, however with conventional gravel. All the mixtures were characterized mechanically through the testing of Resilient Modulus, Static Tensile Strength, fatigue of diametrical compression under controlled stress and static creep. Considering the data of these tests, a numerical study, was made to evaluate the performance of the studied mixtures in the design of a road pavement structure. The steel slag used in this study was shown appropriate to be used as gravel in high modulus asphalt mixtures.
\end{abstract}

\section{INTRODUÇÃO}

Quantidades significativas de resíduos industriais são geradas anualmente e o aproveitamento desses é de suma importância para a conservação do meio ambiente. Dentro deste contexto, destaca-se o uso de escórias de aciaria como agregado em obras rodoviárias, que tem se mostrado como alternativa de redução do custo e da degradação ambiental causada pela extração de materiais de jazidas.

Cada tonelada de aço produzido gera, aproximadamente, $140 \mathrm{~kg}$ de escória de aciaria. Assim, com a crescente produção de aço, chegando, em 2004, a 32,9 milhões e 1,05 bilhão de toneladas no Brasil e no mundo, respectivamente (IBS, 2006), pode-se estimar cerca de 4,6 milhões de toneladas de escória de aciaria depositadas nos pátios das siderúrgicas brasileiras somente no referido ano.

Silva et al. (2002) relatam o aproveitamento de escórias de aciaria por vários países (Inglaterra, Alemanha, Polônia, França, Japão, etc) desde o início do século XX para diversas finalidades. No Brasil, têm-se dados da utilização desse material em pavimentação, desde a década de 70 (IPR, 1988).

Além da utilização de escória apresentar vantagem ambiental de grande valor, ao se evitar a busca por novas jazidas de materiais de construção ao mesmo

\footnotetext{
${ }^{1}$ Hérika Braga de Freitas, Universidade Federal do Rio de Janeiro. Rio de Janeiro, RJ, Brasil. (e-mail: herikabraga@superig.com.br).

2 Laura Maria Goretti da Motta, Universidade Federal do Rio de Janeiro. Rio de Janeiro, RJ, Brasil. (e-mail: laura@coc.ufrj.br).

Manuscrito recebido em 20/2/2008 e aprovado para publicação em 19/5/2008. Este artigo é parte de TRANSPORTES, volume XVI, número 2, dezembro de 2008. ISSN: 1415-7713.
}

tempo em que se reduzem as pilhas de depósito do material nas usinas, pesquisas na área vêm mostrando que o emprego de escória de aciaria em camadas de pavimentos pode ser também uma alternativa viável técnica e economicamente.

Do ponto de vista técnico, as propriedades mecânicas do resíduo são geralmente equivalentes ou superiores a de materiais comumente utilizados em pavimentação, como, por exemplo, constatam Lima et al. (2000) ao verificarem que pavimentos de base e subbases constituídos por escória apresentavam maiores módulos de resiliência e capacidade de distribuição de carga se comparados a estruturas de pavimentos convencionais.

Economicamente, o uso desse resíduo industrial em camadas de pavimentos pode ser viável devido ao baixo custo de obtenção, principalmente em localidades próximas a centros geradores tendo em vista o preço dos transportes, conforme mostra estudo realizado por Alvarenga (2001), além de ser uma alternativa de disposição do material para os produtores, já que o acúmulo crescente do resíduo nos pátios das siderúrgicas gera elevados custos de deposição, exigindo grandes áreas e constantes medidas para atender as leis ambientais vigentes.

Aplicações em misturas asfálticas foram testadas por alguns estudos com sucesso tais como os apresentados por Castelo Branco (2004) e Nóbrega (2007), que estudaram escória de Fortaleza e de Salvador, respectivamente. Evidente que todos levantam cuidados especiais a serem tomados quando se utilizam este tipo de material em misturas asfálticas, mas os resultados mecânicos são animadores.

Outro fato preocupante no Brasil é o atual estado de 
conservação da malha rodoviária nacional. Crescentes volumes e cargas de tráfego nas rodovias brasileiras, têm mostrado a necessidade de novas técnicas de construção, que exijam menores freqüências de manutenção e apresentem maior durabilidade.

Como alternativa para rodovias de alto volume de tráfego, têm-se as chamadas misturas asfálticas de elevados desempenho e durabilidade. Um exemplo dessas misturas são as EME (enrobé a module élevé) ou misturas de módulo elevado, desenvolvidas na França na década de 80 e utilizadas nas camadas de base ou de ligação de pavimentos.

As misturas asfálticas de módulo elevado se diferenciam das misturas convencionais como o concreto asfáltico por apresentarem maior rigidez, obtida pelo uso de ligantes asfálticos de baixa penetração, além de apresentarem bom comportamento em relação à vida de fadiga. Com essa tecnologia, os franceses têm conseguido construir pavimentos de menores espessuras e com características mecânicas superiores a de estruturas convencionais.

Face ao exposto, a pesquisa em questão tem por objetivo geral avaliar, através de estudos predominantemente experimentais (ensaios de laboratório), o uso de escória de aciaria em substituição aos agregados convencionais em misturas asfálticas de módulo elevado, como camadas de ligação ou base de pavimentos asfálticos, a partir da concepção dos pavimentos franceses.

Esta pesquisa faz parte do projeto de pesquisa denominado CTPETRO - PAVIMENTO realizado através de parceria entre o CENPES/PETROBRAS e universidades brasileiras, UFRJ, UFRGS, USP/SP, UFSC e UFC, que, desde 2003, vem desenvolvendo vários experimentos com misturas asfálticas especiais de alto desempenho e durabilidade para pavimentos com grande volume de tráfego.

\section{ESCÓRIAS DE ACIARIA}

O refino do aço gera como resíduo as escórias de aciaria, que são classificadas, de acordo com o forno empregado no processo, em dois tipos: escória LD, proveniente do conversor a oxigênio (LD - LinzDonawitz) e escória elétrica, do forno de arco elétrico (EAF - Electric Arc Furnace).

Uma das características deste material, preocupante quanto ao uso em camadas de pavimentos rodoviários, é seu potencial expansivo, causado, principalmente, pela presença de $\mathrm{CaO}$ e $\mathrm{MgO}$ livres em sua composição. GONTIJO (2006) relata que o uso de escórias não curadas pode ocasionar defeitos no pavimento, tais como trincas radiais e longitudinais no revestimento e deslocamento rotacional de sarjetas.

No entanto, quando o resíduo é devidamente cura- do, têm-se vários exemplos de sucesso no uso do material em pavimentação como em camadas de bases e sub-bases no Brasil e em misturas asfálticas na Europa, Canadá, Austrália e partes dos Estados Unidos (Silva et al., 2002 e Noureldin e McDaniel, 1990).

\section{MISTURAS DE MÓDULO ELEVADO}

Visando melhorar o desempenho mecânico e em contrapartida reduzir as espessuras das camadas asfálticas durante serviços de recuperação de pavimentos urbanos e reestruturação das auto-estradas, foram desenvolvidas na França, na década de 80, as chamadas misturas de módulo elevado. Essas misturas apresentam rigidez superior à das misturas convencionais e se caracterizam pelo uso de ligantes duros e granulometria contínua (Brosseaud, 2002).

As misturas de módulo elevado denominadas EME (enrobé a module élevé) são usadas nas camadas de base ou de ligação, especificadas de acordo com a NF P 98-140 (AFNOR, 1999). Essas misturas são classificadas, em função do diâmetro máximo do agregado, 10, 14 ou 20 mm, em três tipos: EME 0/10, EME 0/14 e EME 0/20. Além desta classificação, a norma francesa, NF P 98-140, também divide as misturas de módulo elevado em classes de desempenho e, segundo esta classificação, as EME são divididas em duas classes, 1 ou 2 cujas características estão indicadas na Tabela 1 .

Tabela 1: Valores especificados para a classe de desempenho das EME (modificada da NF P 98-140)

\begin{tabular}{ccc}
\hline Ensaio & \multicolumn{2}{c}{ EME } \\
\cline { 2 - 3 } & $\mathbf{1}$ & $\mathbf{2}$ \\
\hline Ensaio Duriez, r/R & $\geq 0,70$ & $\geq 0,75$ \\
Resitência ao ATR, \% & $\leq 7,5$ & $\leq 7,5$ \\
Módulo complexo, MPa & $\geq 14.000$ & $\geq 14.000$ \\
Tração direta, MPa & $\geq 14.000$ & $\geq 14.000$ \\
Fadiga, $\mu \varepsilon$ & $\geq 100$ & $\geq 130$ \\
\hline
\end{tabular}

Nesta pesquisa, optou-se por trabalhar com as misturas EME 0/14 (devido a granulometria da escória em estudo) e classe 2 (tipo mais utilizado e considerado de melhor desempenho pelos franceses).

As misturas EME classe 2, geralmente associadas a uma camada de rolamento em concreto asfáltico delgado, de 2 a $3 \mathrm{~cm}$ de espessura, são as mais utilizadas como técnica de manutenção de pavimentos de alto volume de tráfego. Estas misturas além de apresentarem elevada resistência à deformação permanente e boa manutenção das características de superfície (aderência, rugosidade), devido à sua capacidade estrutural, pode-se conseguir reduções de até $25 \%$ de espessura das camadas de pavimento. Faz-se necessário, para conciliar elevada rigidez e resistência à fadiga, o uso de ligantes duros, com penetração a $25^{\circ} \mathrm{C}$ entre 10 
e 35 décimos de milímetros e temperatura de amolecimento anel e bola $\geq 65^{\circ} \mathrm{C}$. Ao utilizar estes ligantes de consistência mais elevada, apesar dos teores obtidos serem relativamente maiores, em torno de $6 \%$ para uma EME 0/14, e das misturas terem baixos volumes de vazios, entre 3 e $6 \%$, consegue-se manter um bom comportamento em relação à fadiga (Brosseaud, 2002; 2006).

Os ligantes empregados podem ser puros ou modificados com polímeros ou aditivos e o teor de ligante mínimo na dosagem é calculado através do chamado módulo de riqueza $(\mathrm{k})$, conforme a Equação 1. Para as misturas da classe 2, o k deve ser no mínimo 3,4.

$$
\text { Teor de ligante }=k \cdot \alpha \cdot \sqrt[5]{\Sigma}
$$

sendo,

$\alpha$ : Coeficiente de correção em função da densidade do agregado $\left(\alpha=2,65 / D_{e f} \mathrm{e}\right.$ $D_{e f}$ a densidade efetiva da mistura de agregados);

$\Sigma$ : $\quad$ Superfície específica calculada segundo a Equação 2:

$$
\Sigma=0,25 \cdot G+2,3 \cdot S+12 \cdot s+135 \cdot f
$$

em que,

G: porcentagem de agregados com diâmetro superior a $6,3 \mathrm{~mm}$;

S: $\quad$ porcentagem de agregados com diâmetro entre 6,3 e 0,315 mm;

s: $\quad$ porcentagem de agregados com diâmetro entre 0,315 e 0,075 mm;

f: $\quad$ porcentagem de agregados com diâmetro inferior a $0,075 \mathrm{~mm}$.

\section{MATERIAIS E MÉTODOS}

Utilizou-se, como agregados graúdo e miúdo, escória de aciaria LD, proveniente da Companhia Siderúrgica de Tubarão (CST), localizada em Serra, região da Grande Vitória, no estado do Espírito Santo. Na Figura 1, tem-se uma amostra da escória da CST utilizada neste estudo na granulometria original.

Os grãos da escória em estudo são de cor cinza claro, com formas variáveis (arredondados e angulares),

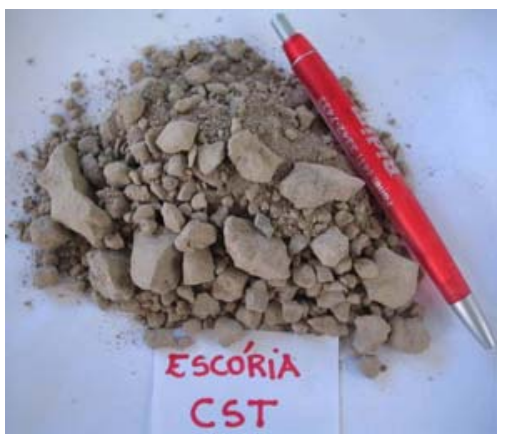

Figura 1: Escória de aciaria utilizada neste estudo textura superficial lisa e aspecto não poroso. Na Tabela 2, é apresentada uma análise química quantitativa desse material.

Tabela 2: Análise química quantitativa da escória em estudo

\begin{tabular}{ccc}
\hline Composto químico & \% em massa & Método de Análise \\
\hline $\mathrm{CaO}$ & 44,40 & EPA 3050B e 6010B \\
$\mathrm{MgO}$ & 8,20 & EPA 3050B e 6010B \\
$\mathrm{Al}_{2} \mathrm{O}_{3}$ & 2,30 & EPA 3050B e 6010B \\
$\mathrm{SiO}_{2}$ & 8,40 & EPA 3050B e 6010B \\
$\mathrm{FeO}$ & 8,00 & $* *$ e * 3500B \\
$\mathrm{P}_{2} \mathrm{O}_{5}$ & 0,21 & Digestão * 4500E \\
$\mathrm{MnO}^{\mathrm{S} O}$ & 4,40 & EPA 3050B e 6010B \\
S & 0,00 & Digestão * 4500E \\
\hline * ALPHA - AWWA 20 Ed. &
\end{tabular}

A escória em estudo foi classificada, quanto a riscos potenciais à saúde pública e ao meio ambiente gerados por resíduos sólidos (NBR 10004/04), como Classe II A (não perigoso e não inerte).

Quanto à análise do potencial expansivo, através do ensaio recomendado pelo método DNER ME 262/94, a escória estudada apresentou valor médio de expansão total, após 14 dias de ensaio, de $0,63 \%$, ou seja, menor que o máximo de 3,0\% especificado pela referida norma. Após 7 dias de ensaio, a expansão foi de 0,31\%, atendendo também a norma americana ASTM D 2940/98, que limita em 0,50\% a expansão máxima para que escórias de aciaria possam ser aplicadas em camadas de base e sub-base de rodovias.

Nesta pesquisa, utilizou-se também agregado convencional, de natureza mineral granítica, proveniente da Pedreira Sepetiba, localizada na região metropolitana do Rio de Janeiro.

Os resultados dos ensaios de caracterização da escória de aciaria e do agregado convencional em estudo são apresentados na Tabela 3. As normas usadas na caracterização foram: DNER ME 081/98 e ASTM C 128/97. Nesta tabela a absorção e a perda por abrasão Los Angeles são expressas em \%.

Como ligantes asfálticos, foram utilizados três tipos: CAP 30/45, CAP 30/45 modificado com $4 \%$ de Sasobit, provenientes da Refinaria Duque de Caxias (REDUC), e Resíduo de Vácuo (RV) da Refinaria Presidente Getúlio Vargas no Paraná (REPAR).

Sasobit é uma parafina ou hidrocarboneto usado na modificação de asfaltos e produzido pela Sasol Wax na África do Sul. Normalmente é vendido em pastilhas e misturado ao betume quente na própria refinaria. É completamente solúvel no ligante a temperaturas maiores que $115^{\circ} \mathrm{C}$, formando uma solução homogênea e reduzindo a viscosidade do ligante. Após o resfriamento, o Sasobit se cristaliza e ligado às moléculas do betume, eleva o ponto de amolecimento e diminui 
Tabela 3: Caracterização da escória e do agregado convencional em estudo

\begin{tabular}{lcccc}
\hline \multirow{2}{*}{ Característica } & \multicolumn{2}{c}{ Escória de Aciaria } & \multicolumn{2}{c}{ Agregado convencional } \\
\cline { 2 - 5 } & Agreg. Graúdo & Agreg. Miúdo & Agreg. Graúdo & Agreg. Miúdo \\
\hline Densidade real & 2,98 & 3,31 & 2,79 & 2,78 \\
Densidade aparente & 2,76 & 2,78 & 2,67 & 2,69 \\
Absorção & 2,60 & 8,96 & 0,80 & 3,01 \\
Perda por abrasão Los Angeles & 17,0 & - & 43,3 & - \\
\hline
\end{tabular}

a penetração do ligante, aumentando desta forma sua estabilidade (resistência à deformação permanente) na temperatura de serviço.

O CAP 30/45 com Sasobit usado neste trabalho vem sendo testado em pesquisas no CENPES/PETROBRAS e ainda não é comercializado no Brasil. O Resíduo de Vácuo (RV REPAR), produto final da destilação do petróleo, também não é comercializado, pois não se enquadra nas especificações brasileiras para ligantes asfálticos para pavimentação, sendo base para produção de CAP especificado.

Esses ligantes em estudo serão designados neste trabalho por: CAP 30/45, CAP 30/45 + Sasobit e RV. Os resultados dos ensaios de caracterização desses ligantes são encontrados em Freitas (2007).

Como o objetivo deste trabalho é comparar a influência do tipo de agregado (escória versus agregado convencional) no desempenho de misturas de módulo elevado, optou-se por realizar o peneiramento da escória e do agregado convencional e enquadrá-los na curva de projeto para diminuir o número de variáveis consideradas.

A adoção da curva granulométrica de projeto foi baseada na hipótese de se trabalhar com uma curva que atendesse, simultaneamente, às recomendações das misturas francesas de módulo elevado, no caso as EME 0/14 da norma NF P 98-140, e também alguma faixa brasileira, no caso a faixa B da norma DNIT 031/06.

Assim, visando utilizar a maior parcela possível de escória, com o mínimo acréscimo de fíler artificial, a composição granulométrica adotada foi de $97 \%$ de escória ou agregado convencional e 3\% de cal hidratada. A curva de projeto é apresentada na Figura 2.

Foram estudados 6 tipos de misturas, convencionalmente designadas por letras e números correspondentes à combinação dos três ligantes e dos dois agregados utilizados, conforme a Tabela 4 .

$\mathrm{O}$ método adotado na dosagem das misturas foi o Marshall e os corpos-de-prova foram compactados com 75 golpes do soquete por face. Antes da compactação, as misturas eram condicionadas em estufa na temperatura de compactação por 2 horas, com o objetivo de simular o efeito do envelhecimento de curto prazo, segundo a especificação da AASHTO PP2/2001.

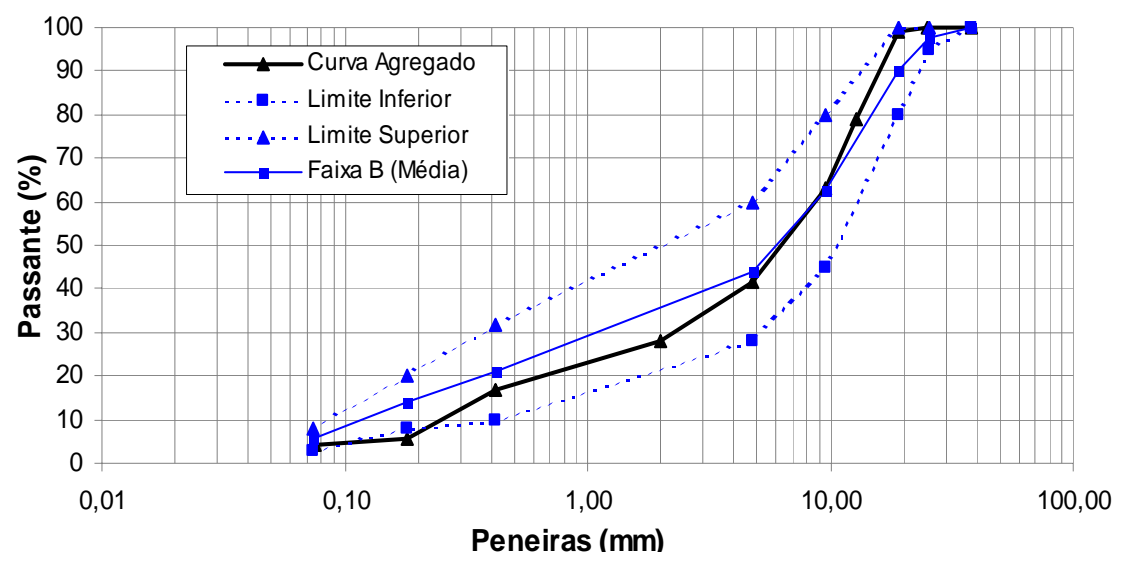

Figura 2: Curva granulométrica de projeto e faixa B do DNER

Tabela 4: Características das misturas asfálticas deste estudo

\begin{tabular}{ccc}
\hline Mistura & Agregado & Ligante \\
1A & Escória de Aciaria & RV \\
1B & Convencional (brita de rocha) & RV \\
2A & Escória de Aciaria & CAP 30/45+SASOBIT \\
2B & Convencional (brita de rocha) & CAP 30/45+SASOBIT \\
3A & Escória de Aciaria & CAP 30/45 \\
3B & Convencional (brita de rocha) & CAP 30/45 \\
\hline
\end{tabular}


As misturas asfálticas em estudo foram caracterizadas mecanicamente através dos ensaios de Módulo de Resiliência (MR), Resistência à Tração estática por compressão diametral (RT), fadiga por compressão diametral à tensão controlada e compressão axial estática (creep estático). Os ensaios de MR, RT e fadiga foram realizados à temperatura de $25^{\circ} \mathrm{C}$, enquanto que a temperatura do ensaio de creep estático foi de $40^{\circ} \mathrm{C}$.

\section{RESULTADOS E DISCUSSÕES}

\subsection{Teor de projeto}

Para as misturas com escória, o teor de projeto foi adotado a partir do critério da trabalhabilidade na homogeneização destas, tendo sido testados teores de ligante de 6,0 a 8,0\% e variação de 0,5\%. Assim, pela trabalhabilidade, adotou-se como 7,0\% o teor de projeto das misturas $1 \mathrm{~A}, 2 \mathrm{~A}$ e $3 \mathrm{~A}$, sendo o menor teor a apresentar, simultaneamente, facilidade de mistura e recobrimento adequado dos grãos. O módulo de riqueza calculado pela Equação 1 atende ao critério mínimo dado na Tabela 1. A verificação dos parâmetros volumétricos foi usada como critério a posteriori, ou seja, conferidos os valores obtidos com este teor de ligante, porém não pretendendo alcançar o tradicional 4\% de vazios dos padrões americanos já que se trata de mistura diferenciada e que será utilizada como base. Todos os parâmetros volumétricos podem ser vistos em Freitas (2007).

Para as misturas com agregado convencional, 1B, 2B e 3B, adotou-se o teor de projeto de 5,0\%, teor mínimo necessário para atender o critério de módulo de riqueza igual a 3,4 (Equação 1) estipulado pelos franceses para misturas EME classe 2.

\subsection{Módulo de Resiliência (MR)}

Apresenta-se, na Figura 3, os valores médios de três determinações de MR das misturas estudadas nos seus teores de projeto. Verifica-se que os maiores valores foram obtidos nas misturas com o CAP 30/45 com Sasobit. Para os demais ligantes, verificou-se que as misturas com escória apresentaram maiores valores de MR que as misturas com agregado convencional. Es-

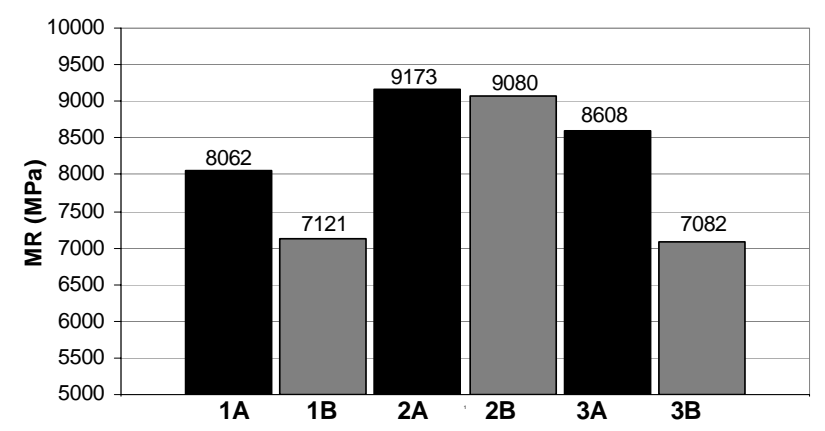

Figura 3: Valores médios de MR de todas as misturas em estudo nos teores de projeto sas tendências também foram observadas nos ensaios de MR das misturas em estudo em outros teores de ligante (Freitas, 2007).

\subsection{Resistência à tração estática por compressão diametral (RT)}

São apresentados, na Figura 4, os valores médios de três determinações de RT das misturas em estudo nos seus teores de projeto. Os valores de RT foram maiores para as misturas com escória de aciaria comparadas àquelas com agregado convencional ao se utilizar o ligante CAP 30/45, enquanto que para os demais ligantes em estudo, não houve diferença significativa entre os valores de RT das misturas com escória e com agregado convencional. O estudo estatístico de comparação está apresentado em Freitas (2007).

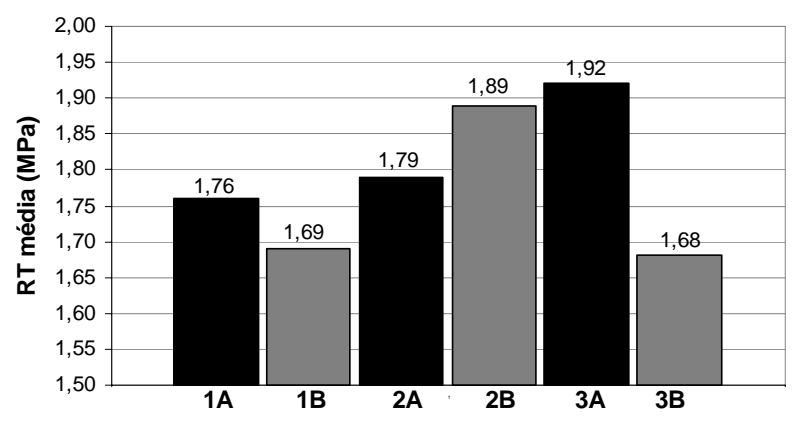

Figura 4: Valores médios de RT de todas as misturas em estudo nos teores de projeto

\subsection{Deformação permanente por compressão axial - Creep estático}

São apresentados na Tabela 5, os valores de deformação permanente, obtidos da média de três corpos-deprova ensaiados, para as misturas com escória (1A, $2 \mathrm{~A}$ e $3 \mathrm{~A}$ ) e com agregado convencional (2B e 3B) nos

Tabela 5: Deformação específica permanente (\%) das misturas com escória (1A, 2A e 3A) e com agregado convencional (2B e 3B) obtidas do ensaio de creep estático

\begin{tabular}{ccc}
\hline Mistura & Deformação específica (\%) & Desvio padrão \\
1A & 0,177 & 0,081 \\
2A & 0,101 & 0,015 \\
2B & 0,085 & 0,031 \\
3A & 0,152 & 0,002 \\
3B & 0,278 & 0,058 \\
\hline
\end{tabular}

seus respectivos teores de projeto, 7,0 e 5,0\%. Não foi possível realizar o ensaio na mistura $1 \mathrm{~B}$ por problemas na prensa na época desta pesquisa. As misturas com CAP 30/45 + Sasobit apresentaram menores valores de deformação, apesar da diferença entre todas as misturas terem sido pequenas.

\subsection{Fadiga}

Estão apresentadas na Tabela 6 as equações obtidas no 
ensaio de fadiga, em termos de diferença de tensões, para as misturas asfálticas estudadas nesta pesquisa. Maiores detalhes podem ser vistos em Freitas (2007).

Tabela 6a: Parâmetros do ensaio de fadiga das misturas com escória (1A, 2A e 3A)

\begin{tabular}{cccc}
\hline Mistura & $\boldsymbol{K}$ & $\boldsymbol{n}$ & $\boldsymbol{R}^{\mathbf{2}}$ \\
\hline 1A & $8,7 \times 10^{4}$ & 4,5 & 0,973 \\
2A & $4,7 \times 10^{5}$ & 5,0 & 0,978 \\
3A & $5,4 \times 10^{4}$ & 3,9 & 0,996 \\
\hline
\end{tabular}

Tabela 6b: Parâmetros de fadiga das misturas com agregado convencional (1B, $2 \mathrm{~B}$ e $3 \mathrm{~B})$

\begin{tabular}{cccc}
\hline Mistura & $\boldsymbol{K}$ & $\boldsymbol{n}$ & $\boldsymbol{R}^{\mathbf{2}}$ \\
\hline 1B & $3,9 \times 10^{4}$ & 3,8 & 0,979 \\
2B & $1,3 \times 10^{5}$ & 4,3 & 0,962 \\
3B & $2,1 \times 10^{4}$ & 3,5 & 0,969 \\
\hline
\end{tabular}

\subsection{Análise numérica pelo FEPAVE2}

Para avaliar o comportamento das misturas em estudo, com base nos resultados obtidos nos ensaios mecânicos, utilizou-se o programa numérico FEPAVE2. Escolheu-se o pavimento do Lote 7 da Rodovia Carvalho Pinto (Figura 5), construído em 1996 e que desde então vem apresentando bom desempenho sob condições de tráfego pesado, como estrutura comparativa das análises realizadas com as misturas de módulo elevado em estudo. As características físicas e mecânicas dos materiais do trecho estão em Freitas (2007).

\begin{tabular}{ccc}
\hline Capa - CBUQ & MR=51.424 kgf/cm ${ }^{2}$ & $h=12 \mathrm{~cm}$ \\
\hline Base - BGS & $M R=4310 \sigma_{3}{ }^{0,487} \sigma_{d}{ }^{-0,024}$ & $h=12 \mathrm{~cm}$ \\
\hline Sub-base - BGTC & $M R=90.000 \mathrm{kgf} / \mathrm{cm}^{2}$ & $\mathrm{~h}=17 \mathrm{~cm}$ \\
\hline Subleito - LG' & $M R=4000 \sigma_{3}{ }^{0,224}{\sigma_{d}}^{-0,168}$ &
\end{tabular}

Figura 5: Estrutura comparativa da Rodovia Carvalho Pinto

Como critérios de aceitação, foram adotados:

\section{- Deflexão máxima admissível $\left(D_{a d m}\right)$}

$$
\log \left(D_{\text {adm }}\right)=3,148-0,188 \cdot \log N_{p} \quad\left[10^{-2} \mathrm{~mm}\right]
$$

Na falta de outra equação que melhor representasse as condições de rigidez e deslocamentos limites para as estruturas em estudo, optou-se por utilizar a Equação 3 (DNER PRO 269/94), porém deve-se salientar que essa equação foi desenvolvida com base num banco de dados com estruturas típicas brasileiras e misturas asfálticas com faixa de módulos resilientes (3.000 a $6.000 \mathrm{MPa}$ ), diferentes dos valores das misturas em estudo e não se aplica diretamente para bases cimentadas.

\section{- Diferença de tensões no revestimento}

A diferença de tensões foi considerada a partir das curvas de fadiga obtidas em laboratório para as mistu- ras em estudo mostradas na Tabela 6 (a e b) e adotando-se o fator campo laboratório (FCL) igual a $10^{4}$ (Pinto, 1991). Deve-se salientar também que este FCL foi baseado em estudos com misturas diferentes destas aqui pesquisadas.

- Tensão vertical admissível no subleito, $\sigma_{\text {vadm }}$, (Heukelom e Klomp, 1962)

$$
\sigma_{\text {vadm }}=\frac{0,006 \cdot M R_{\text {médio }}}{(1+0,7 \cdot \log N)} \quad\left[\mathrm{kgf} / \mathrm{cm}^{2}\right]
$$

Optou-se por utilizar nas análises com as misturas em estudo, uma estrutura típica francesa de misturas de módulo elevado, em que não há necessidade de se utilizar revestimento com função estrutural, já que nesses casos, a capa tem apenas a função de garantir proteção à camada subjacente e conforto ao rolamento. Assim, utilizou-se um revestimento em SMA de módulo de resiliência igual a 2.193 MPa, conforme indicado em Mourão (2003).

Na Figura 6, tem-se um esquema da estrutura adotada no dimensionamento com o FEPAVE2, em que se considerou um revestimento de SMA de $3 \mathrm{~cm}$, as misturas em estudo como camada de ligação, variando-se as espessuras, uma base de brita graduada com $12 \mathrm{~cm}$ de espessura e um subleito argiloso laterítico LG', os dois últimos com as mesmas características da estrutura comparativa. Para todas as misturas, foram utilizados os valores de MR médio, MR médio menos um desvio e MR mais um desvio, visando aplicar confiabilidade ao dimensionamento. Na Figura 7, tem-se um resumo das estruturas dimensionadas para um tráfego de $10^{8}$ e nível de confiança de 99,9\% para as várias misturas testadas neste estudo.

\begin{tabular}{ccc}
\hline Capa - SMA & MR=21.930 kgf/cm & $\mathrm{h}=3 \mathrm{~cm}$ \\
\hline LIGAÇÃO - Misturas em estudo & MR=variável & $\mathrm{h}=$ variável \\
\hline Base - BGS & $\mathrm{MR}=4310 \sigma_{3}{ }^{0,487} \sigma_{\mathrm{d}}{ }^{-0,024}$ & $\mathrm{~h}=12 \mathrm{~cm}$ \\
\hline Subleito - LG' & $\mathrm{MR}=4000 \sigma_{3}{ }^{0,224}{\sigma_{\mathrm{d}}}^{-0,168}$
\end{tabular}

Figura 6: Estrutura adotada para análise da aplicação das misturas em estudo

Nas misturas com escória, os critérios de projeto seriam atendidos com $6 \mathrm{~cm}$ de espessura ao utilizar o CAP 30/45 + Sasobit (mistura 2A), enquanto que para os demais ligantes (misturas 1A e 3A) seriam necessários $8 \mathrm{~cm}$ de camada intermediária. Considerando-se as misturas com agregado convencional, com o CAP 30/45 (mistura 3B) seria necessária uma camada asfáltica de $10 \mathrm{~cm}$, enquanto que as misturas $1 \mathrm{~B}$ e $2 \mathrm{~B}$ atenderiam aos critérios de projeto com $8 \mathrm{~cm}$ de espessura.

Ao analisar a influência do agregado no dimensionamento da estrutura adotada, verifica-se que para todos os ligantes, as misturas com escória apresentaram, 
na maioria dos casos, melhor desempenho em relação às misturas com agregado convencional. Obtiveram-se com a estrutura adotada, reduções significativas na espessura do pavimento original, chegando a 50\% no caso em que se aplicou a mistura com escória e CAP 30/45 com Sasobit como camada de ligação.

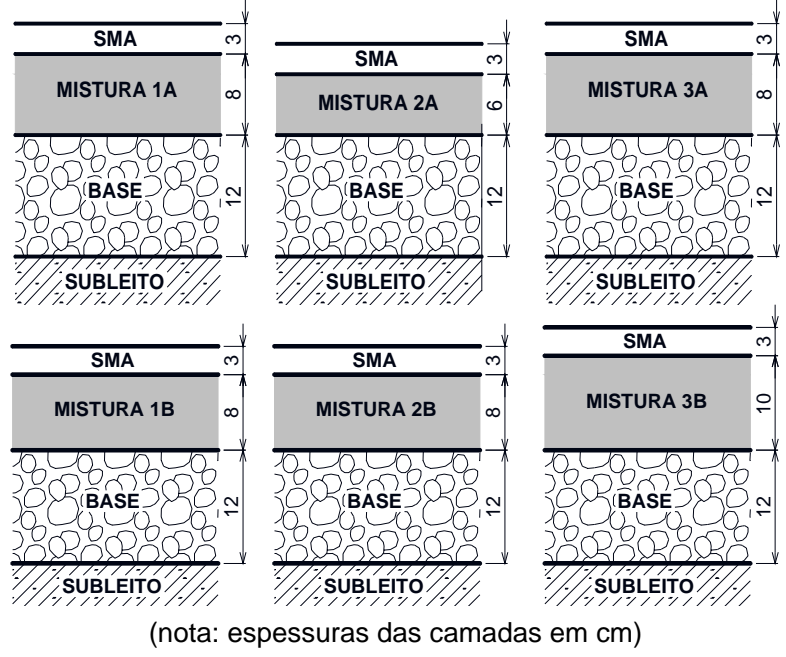

Figura 7: Resumo das estruturas dimensionadas com o FEPAVE2, utilizando as misturas em estudo como camada de ligação

No entanto, deve-se salientar que, por se tratar de misturas não-convencionais, as análises numéricas foram realizadas apenas como uma forma de se comparar as misturas produzidas entre si, já que os critérios utilizados no dimensionamento, tais como o FCL (Pinto, 1991), foram desenvolvidos para outros tipos de materiais, não se podendo afirmar que sejam todos eles válidos igualmente para as misturas ensaiadas, portanto as espessuras são indicativas para o desempenho considerando iguais condições de análise.

Com o objetivo de comparar o desempenho das misturas de módulo elevado estudadas em relação a materiais cimentados quanto à vida de fadiga, analisou-se também a mesma estrutura da Figura 6, porém com a camada de ligação asfáltica substituída por um concreto compactado a rolo (CCR). As características adotadas para o CCR (MR=18.000 $\mathrm{MPa}$ e $\mathrm{RT}=1,55$ $\mathrm{MPa}$ ), retiradas da ABPv (1995), fazem parte da pesquisa de Trichês (1993). Para a vida de fadiga da estrutura com o CCR apresentar mesma ordem de grandeza da vida de fadiga $\left(\mathrm{N}=10^{8}\right)$ da estrutura composta pelas misturas asfálticas em estudo, seria necessário utilizar espessura igual a $14 \mathrm{~cm}$ de CCR $\left(\sigma_{\mathrm{t}}=0,76\right.$ MPa e $\mathrm{N}=3,6 \times 10^{8}$ ).

Ao comparar o desempenho das misturas asfálticas estudadas ao do CCR na estrutura considerada (Figura 6), verifica-se que, apesar do valor de MR do CCR ser aproximadamente o dobro das misturas asfálticas em estudo, estas apresentaram melhor comportamento em relação à vida de fadiga. Note-se também que, embora o MR tenha sido o dobro, a RT do CCR deste exemplo é da mesma ordem de grandeza das resistências das misturas asfálticas com escória, ou seja, a relação MR/RT é da ordem de 11.000 vezes para o CCR, ressaltando a cimentação do tipo frágil dada pelo cimento Portland em relação à dúctil do cimento asfáltico. Daí a exigência de maiores espessuras iniciais para o CCR.

\section{CONCLUSÕES E SUGESTÕES}

Com base nos resultados desta pesquisa, foi possível concluir que:

- escória de aciaria deste estudo atendeu às expectativas quanto ao uso como agregado em misturas asfálticas de módulo elevado, apresentando características físicas e mecânicas tão boas quanto e, em alguns casos, até superiores a do agregado convencional analisado. Apesar do maior teor de ligante utilizado em relação ao das misturas com agregado convencional, devese levar em consideração o custo global para cada caso (distância de transporte ao local da obra, preço do agregado, etc), além do bem ambiental ao se aproveitar um resíduo;

- os maiores valores de MR foram obtidos nas misturas com o CAP 30/45 + Sasobit, sendo iguais para os dois tipos de agregado estudados. Já para os ligantes RV e CAP 30/45, os maiores valores de MR foram obtidos nas misturas com escória;

- apenas com o CAP 30/45, os valores de RT foram maiores nas misturas com escória, enquanto que, para os demais ligantes em estudo, não houve influência do tipo de agregado na RT. Quanto ligante utilizado, em geral, as misturas com o CAP 30/45 com Sasobit apresentaram maiores valores de RT;

- os valores de deformação permanente, obtidos pelos ensaios de creep estático, foram considerados pequenos em relação aos valores geralmente encontrados para misturas convencionais. Os menores valores foram obtidos com o CAP 30/45 + Sasobit;

- pela análise numérica, verificou-se que as misturas com o CAP 30/45 + Sasobit apresentaram o melhor desempenho, obtendo-se menores espessuras finais para a estrutura adotada, ao se considerar o mesmo tráfego $\left(10^{8}\right)$ e nível de confiabilidade (99,9\%);

- analisando-se a influência do agregado no dimensionamento da estrutura estudada pelo FEPAVE2, para todos os ligantes em estudo, as misturas com escória apresentaram melhor desempenho em relação às misturas com agregado 
convencional;

- houve reduções, em relação à espessura final da estrutura comparativa (Rodovia Carvalho Pinto), de até 50\% (mistura com escória e CAP 30/45 + Sasobit) ao se utilizar as misturas em estudo, o que mostra que, apesar de apresentarem rigidez muito próximas a de materiais estabilizados com cimento, as misturas de módulo elevado podem ter como vantagem maior resistência à fadiga que os materiais cimentados. No entanto, deve-se salientar que as espessuras finais obtidas para as misturas em estudo podem não ser exatamente as calculadas, já que ainda não são conhecidos dados mais representativos do desempenho das mesmas, tais como o Fator Campo Laboratório aplicável a estas.

Como sugestões de pesquisas futuras têm-se:

- acompanhar um trecho experimental com as misturas estudadas para avaliar o desempenho em condições de serviço;

- fazer um estudo detalhado de custos para comparar o uso da escória de aciaria como agregado em misturas de módulo elevado com o de agregados convencionais, considerando-se distâncias de transporte, reduções de espessuras, custo dos materiais, etc;

- como a absorção do agregado miúdo da escória estudada foi bastante elevada, substituir esta fração das misturas por agregados convencionais, tais como areia ou pedra britada, com o objetivo de diminuir o teor de ligante;

- realizar ensaios de MR em prensa semelhante à utilizada pelos franceses para verificar se a faixa de valores de MR obtidas no Brasil está próxima aos de valores de módulos elásticos das misturas francesas, já que os ensaios para a obtenção desse parâmetro são diferentes nos dois países.

\section{REFERÊNCIAS BIBLIOGRÁFICAS}

AASHTO - American Association of State Highway and Transportation Officials, 2001, PP2, Standard Practice for Mixture Conditioning of Hot Mix Asphalt (HMA).

ABNT - Associação Brasileira de Normas Técnicas, 2004, NBR 10004, Resíduos Sólidos - Classificação.

ABPv - Associação Brasileira de Pavimentação, 1995, Boletim Técnico n ${ }^{\circ}$ 16, Catálogo de Curvas de Fadiga.

AFNOR - Association Française de Normalisation, 1999, NF P 98-140, Enrobés Hidrocarbonés - Couches d'assises: Enrobés à Module Élevé (EME).

Alvarenga, J. C. A., 2001, Um Estudo para a Avaliação Estrutural e Econômica de Pavimentos Flexíveis de Escória de Aciaria. Dissertação de M. Sc., COPPE/UFRJ, Rio de Janeiro, RJ, Brasil.

ASTM - American Society for Testing and Materials, 1997, C 128, Standard Test Method for Specific Gravity and Absorption of Fine Aggregate.

ASTM - American Society for Testing and Materials, 1998, D 2940, Standard Specification for Graded Aggregate Material for Bases or Subbases for Highways or Airport.
Brosseaud,Y., 2002, "Les Enrobes Français: Panorama des Techniques Bitumineuses, Bilan de Comportement”. $16^{\circ}$ Encontro de Asfalto, Rio de Janeiro, RJ, Dezembro.

Brosseaud,Y., 2006, “Les Enrobés à Module Eleve: Bilan de L’ expérience de Française et Transfert de Technologie”. $7^{\circ}$ Congrès National de la Route, Maroc, Novembre.

Castelo Branco, V. T. F., 2004, Caracterização de Misturas Asfálticas com o Uso de Escória de Aciaria como Agregado. Dissertação de M.Sc., COPPE/UFRJ, Rio de Janeiro, RJ, Brasil.

DNER - Departamento Nacional de Rodagem, 1994, EM 262, Escórias de Aciaria para Pavimentos Rodoviários.

DNER - Departamento Nacional de Rodagem, 1994, PRO 269/94, Projeto de Restauração de Pavimentos Flexíveis.

DNER - Departamento Nacional de Rodagem, 1998, ME 081, Agregados - Determinação da Absorção e da Densidade de Agregado Graúdo.

DNIT - Departamento Nacional de Infra-Estrutura de Transportes, 2006, ES 031, Pavimentos Flexíveis - Concreto Asfáltico.

Freitas, H. B., 2007, Misturas Asfálticas de Módulo Elevado Com Uso de Escória de Aciaria como Agregado. Dissertação de M.Sc., COPPE/UFRJ, Rio de Janeiro, RJ, Brasil.

Gontijo, P. R. A., 2006, "Pavimentos Compostos com Escórias de Aciaria”, Revista Pavimentação, ano 1, n. 3 (Julho), pp. 42-54.

Heukelom, W. e Klomp, A. J. G., 1962, Dynamic testing as means of controlling pavements during and after construction. Proceedings, 1 INTER. CONSTRUCT. DESIGN OF ASPHALT PAVEM., Ann Arbor, Univ. Michigan, p. 667-679.

IBS, 2006 - Instituto Brasileiro de Siderurgia, www.ibs.org.br 19/03/2006.

IPR - Instituto de Pesquisas Rodoviárias, 1988, Escórias Siderúrgicas Material de Múltiplas Aplicações, MT/DNER/IPR.

Lima, N. P. de, Nascimento, J., F. do, Filho, V., P., C., V. et al., 2000, “Pavimentos de Alto Desempenho Estrutural Executados com Escória de Aciaria”. 10a Reunião de Pavimentação Urbana, $\mathrm{n}^{\circ}$ 1.15, Uberlândia, MG, Agosto.

Mourão, F. A. L., 2003, Misturas Asfálticas de Alto Desempenho Tipo SMA. Dissertação de M.Sc., COPPE/UFRJ, Rio de Janeiro, RJ, Brasil.

Nóbrega, L. M., 2007, Caracterização Mecânica de Misturas Asfálticas Utilizando Escória de Ferroliga de Manganês como Agregado. Dissertação de M.Sc., UFBA, Salvador, BA, Brasil.

Noureldin, A. S. e McDaniel, R. S., 1990, "Evaluation of Surface Mixtures of Steel Slag and Asphalt”, Transportation Research Record, n. 1269, pp. 133-149.

Pinto, S., 1991, Estudo do Comportamento à Fadiga de Misturas Betuminosas e Aplicação na Avaliação Estrutural de Pavimentos. Tese de D.Sc., COPPE/UFRJ, Rio de Janeiro, RJ, Brasil.

Silva, E. A. da, Mendonça, R., L de. e Dobele, C., H., M., 2002, "Utilização da Escória de Aciaria em Todas as Camadas do Pavimento”. $16^{\circ}$ Encontro de Asfalto, trabalho convidado, Rio de Janeiro, RJ, Dezembro. 